\title{
Thermal Dissolution of Shengli Lignite in Isometric Methanol and Ethyl Acetate Mixed Solvent - Molecular Composition of the Extract and the Role of Ethyl Acetate
}

\author{
Xingshun Cong ${ }^{1, a}$, Min $\mathrm{Li}^{2,}$ b , Hangyu Gao ${ }^{1, \mathrm{c}}$, Lingling Zhang ${ }^{1, \mathrm{~d}}$, Niancun $\mathrm{Ji}^{1, \mathrm{e}}$ \\ ${ }^{1}$ Department of Chemistry, Zaozhuang University, Zaozhuang, 277160, China \\ ${ }^{2}$ College of Chemical Engineering, China University of Petroleum, Qingdao, 266580, China \\ aemail: cxshouse@sohu.com, bemail: zaoyuanlimin@126.com, email: 18463287480@163.com, \\ demail:18463287173@163.com, eemail:m17863252269@163.com
}

\section{Keywords: Shengli Lignite; Phenols; Thermal Dissolution Mechanism; Hydrogen Bond}

\begin{abstract}
Thermal dissolution (TD) of Shengli lignite was carried out in isometric solvent of methanol and ethyl acetate (EA), methanol, and EA to offer the thermally soluble fractions 1-3 $\left(F_{1}-F_{3}\right)$, respectively. $F_{1}-F_{3}$ were analyzed by gas chromatography/mass spectrometry and direct analysis in real-time ionization source/ion trap mass spectrometry (DARTIS/IT-MS). Phenols with 1-4 methyls are the most abundant composition in the extract. The DARTIS/IT-MS analysis shows that the main peaks of the molecular weight distribution of the extract are located at $\mathrm{m} / \mathrm{z} 120-340$, and trace signals are still observed at $\mathrm{m} / \mathrm{z}$ 640. The extract yield of $F_{1}$ is higher than those of $F_{2}$ and $\mathrm{F}_{3}$, even the sum of $\mathrm{F}_{2}$ and $\mathrm{F}_{3}$ yields. The roles of EA to lignite TD were investigated by experimental comparison and molecular dynamics simulation. Both the increase in nucleophilicity and the $\mathrm{O}-\mathrm{H}$ bond extension of methanol due to the formation of intermolecular hydrogen bonds between methanol and EA make the nucleophilic attacking and the scission of O-H bond easier. The transesterification reaction with EA occurs during lignite TD. These results demonstrate that the TD process can be slightly adjusted by altering the microstructure and microenvironment of methanol.
\end{abstract}

\section{Introduction}

Understanding of lignite structure, especially macromolecular structure, and then directionally cleaving the specific chemical bonds of lignites to produce clean fuels and value-added chemicals are challenging and attractive tasks. The room-temperature extraction of lignites is a typical method to examine lignite structure [1-3]. However, unlike bituminous coals, the extraction yields of lignites are very small even with isometric carbon disulfide and $N$-methyl-2-pyrrolidinone mixed solvent $[4,5]$ because lignites retain macromolecular species from coal-forming plants. Hence, it is of the utmost importance to enhance the dissolvability of lignites via thermal dissolution (TD) in low-carbon alkanols under relatively mild condition (usually $250-350{ }^{\circ} \mathrm{C}, 4-17 \mathrm{MPa}$ ). Wei et al [6] investigated alkanolysis of Huolinguole lignite in methanol and in ethanol sequentially at different temperatures and concluded that the nucleophilicity and the solubility parameter of alkanols affected the amount of alkanolysis products. To our knowledge, no reports were issued on TD of any coal in isometric methanol and ethyl acetate (EA) mixed solvent (IMEAMS). The objectives of this research are to analyze molecular components of TD organic matter (TDOM) of Shengli lignite (SL, a Chinese lignite) in IMEAMS and to investigate the TD mechanisms to understand the influence of EA on TD of SL.

\section{Experimental}

SL collected form Shengli coal mine, Xilinhaote, Inner Mongolia, China, was pulverized to pass through a 200-mesh sieve (particle size $<75 \mu \mathrm{m}$ ), desiccated in a vacuum at $80{ }^{\circ} \mathrm{C}$ for $24 \mathrm{~h}$, and then stored at room temperature in a well-sealed wide-necked bottle to minimize undesirable oxidation. The proximate and ultimate analyses of SL are described elsewhere [7,8]. Methanol, EA, carbon disulfide and acetone in analytically pure grade were distilled with a Büchi R-210 rotary evaporator 
prior to use.

About $1 \mathrm{~g}$ SL and ca. $20 \mathrm{~mL}$ IMEAMS were put into a $100 \mathrm{~mL}$ stainless-steel, magnetically stirred autoclave. The autoclave was heated to $300{ }^{\circ} \mathrm{C}$ and maintained at the temperature for $2 \mathrm{~h}$. Then the autoclave was immediately cooled to room temperature in a water bath and the reaction mixture was exhaustively extracted with IMEAMS to afford IMEAMS soluble fraction $\left(\mathrm{F}_{1}\right)$ and extraction residue. TD of $c a .1 \mathrm{~g} \mathrm{SL}$ in $20 \mathrm{~mL}$ methanol and in $20 \mathrm{~mL}$ EA were also carried out respectively as a comparison to afford methanol soluble fraction $\left(\mathrm{F}_{2}\right)$ and EA soluble fraction $\left(\mathrm{F}_{3}\right)$.

The gas chromatography/mass spectrometry (GC/MS) analyses of the extracts were performed on a Hewlett-Packard 6890/5973 gas chromatograph/mass spectrometer equipped with a HP-5MS capillary column and a quadrupole mass analyzer (scanned form $\mathrm{m} / \mathrm{z} 33$ to 550 ). The molecular weight distribution (MWD) of the extract was determined using an Agilent XCT ion trap multiple-stage mass spectrometer fitted with an IonSense SVP Source direct analysis in real time ionization source (DARTIS). The TD yields of the extracts were calculated according to the formula $Y_{\mathrm{F}}=W_{\mathrm{F}} / W_{\mathrm{SL}, d a f}$, where $W_{\mathrm{F}}$ and $W_{\mathrm{SL} \text {,daf }}$ denote weights of the desolventized extracts (solvent-removed $F_{1}, F_{2}$ and $F_{3}$ ) and SL sample on dry and ash free basis, respectively.

\section{Results and discussion}

Molecular composition of the extracts: All the extracts $\left(F_{1}-F_{3}\right)$ were analyzed by GC/MS. The relative contents (RCs) and number of compounds of group components are summarized in Figure 1. In total, 196, 147 and 128 organic compounds were identified in $F_{1}, F_{2}$ and $F_{3}$, respectively, and they can be classified into arenes, phenols, alkanes, methyl esters (MEs), ethyl esters (EEs), alkenes, alkoxyarenes (AAs; including methoxyarenes and ethoxyarenes), organonitrogen compounds (ONCs) and other compounds (OCs). Phenols are the most abundant compounds in $\mathrm{F}_{1}$ and $\mathrm{F}_{2}$, both accounting for $c a .40 \%$, whereas only $21 \%$ were detected in $\mathrm{F}_{3}$. Although RCs of phenols in $\mathrm{F}_{1}$ and $\mathrm{F}_{2}$ are similar, considerably more kinds of phenols were detected in $\mathrm{F}_{1}$ than that in $\mathrm{F}_{2}$.

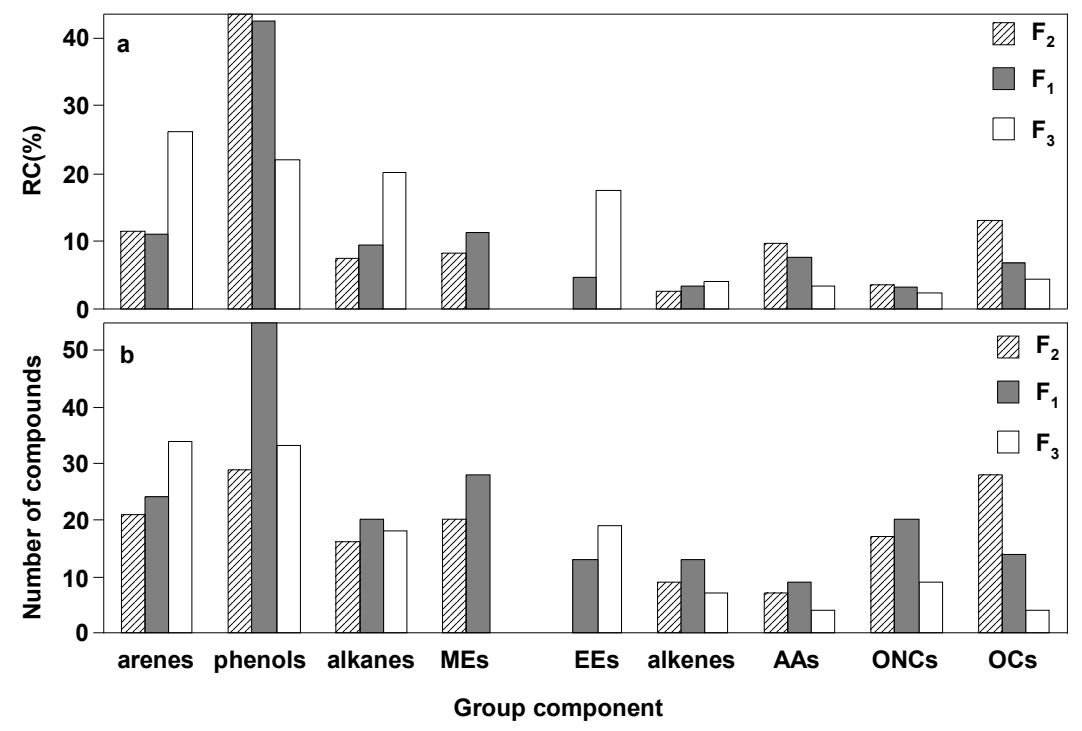

Fig. 1. RCs (a) and number of compounds (b) of group compositions detected in $\mathrm{F}_{1}, \mathrm{~F}_{2}$ and $\mathrm{F}_{3}$

The total ion chromatogram (TIC) of $F_{1}$ is shown in Figure 2. In total, 24 arenes, 55 phenols, 20 alkanes, 28 MAs, 13 EEs, 13 alkenes, 9 AAs, 20 ONCs and 14 OCs were identified. Aliphatic hydrocarbons consist of $n$-alkanes $\left(\mathrm{C}_{15} \sim \mathrm{C}_{27}\right)$ and $n$-alkenes $\left(\mathrm{C}_{14} \sim \mathrm{C}_{23}\right.$, without $\mathrm{C}_{15}, \mathrm{C}_{17}$ and $\left.\mathrm{C}_{21}\right)$, except 5 hopanoids (peaks 185, 187, 189, 191 and 193), 1 cyclopentane (peak 133), 2 cycldienes (peak 7: tetramethylcyclohexadiene and peak 15: dimethylcyclopentadiene) and 2 hexadienes (peaks 18 and 37). Normal fatty acid esters and alkylbenzoic acid esters are the main components in MAs and EEs, accounting for ca. $85 \%$ and $15 \%$, respectively. All compounds belonged to the arenes, phenols, AAs and OCs are listed in Table 1. Noteworthily, the RC of oxygen-containing compounds in $\mathrm{F}_{1}$ is $74 \%$, indicating that $\mathrm{SL}$ contains substantial amounts of oxygen in the form of carboxyl, phenolic hydroxyl, carbonyl and aromatic ether groups. 


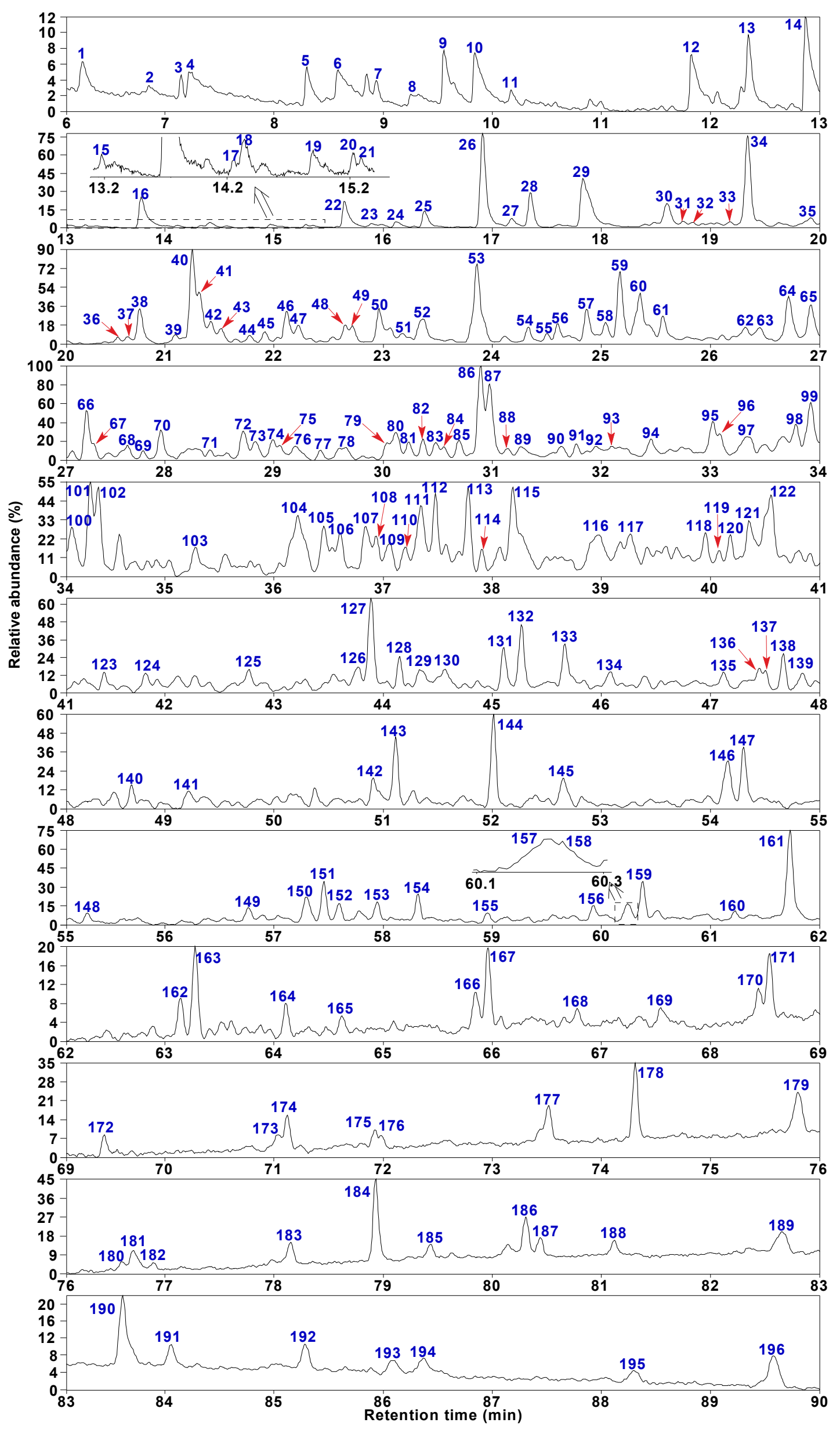

Fig. 2. TIC of $F_{1}$ 
Table 1. Arenes, phenols, OCs and AAs detected in $\mathrm{F}_{1}$

\begin{tabular}{|c|c|c|c|c|c|}
\hline \multicolumn{2}{|r|}{ Arenes } & \multicolumn{2}{|c|}{ Phenols } & \multicolumn{2}{|r|}{ OCs } \\
\hline Peak & Compounds & Peak & Compounds & $\overline{\text { Peak }}$ & Compounds \\
\hline 3 & Toluene & 16 & Phenol & 8 & Dimethyl Sulfoxide \\
\hline 90,92 & Trimethylindene & 26,29 & Methylphenol & 25 & Dimethyl CP \\
\hline 98 & Dimethylnaphthalene & $34,38,40,41,46-48$ & $\mathrm{C}_{2}$-Phenol & 27 & Methylcyclohex-2-enone \\
\hline 107 & Hexamethylbenzene & 42,49 & Methoxymethylphenol & 28,30 & Trimethyl CP \\
\hline 114 & Dimethylisopropyl THN & 43,51 & Ethoxyphenol & 35,45 & Tetramethyl CP \\
\hline 116,122 & Trimethylnaphthalene & $50,57,61,62$ & Methylethylphenol & 44 & $\mathrm{HTMCH}$ \\
\hline 127,129 & Dimethylisopropylnaphthalene & $53,59,64,65,71$ & Trimethylphenol & 80 & MTPE \\
\hline 134 & Tetramethylnaphthalene & 56 & Dihydroxy AP & 100,101 & Tert-butylphenylmethanol \\
\hline 135 & Tetramethyl THN & 58 & Isopropylphenol & 113 & Tetramethyldihydroindenone \\
\hline 139 & Anthracene & 63 & Methoxyethylphenol & 125,126 & Methylethylbenzothiophene \\
\hline 145 & Triisopropylbenzene & $66,68,72,74,76-78,81-83,86,87,99$ & $\mathrm{C}_{4}$-Phenol & & \\
\hline 149 & Dimethylphenanthrene & 84 & Hydroxymethyl AP & & AAs \\
\hline 150 & Pyrene & 85 & HMPE & Peak & Compounds \\
\hline 153 & Butylhexylnaphthalene & 88,96 & Tert-butylmethylphenol & 39 & Dimethoxybenzene \\
\hline 155 & Fluoranthene & 94,103 & Methoxytrimethylphenol & 52 & Methoxyethoxybenzene \\
\hline 156 & Trimethylphenanthrene & 102 & Trimethylbenzenediol & 60 & Methoxyethylbenzene \\
\hline 161 & Methylisopropylphenanthrene & $104,106,110,111,118$ & $\mathrm{C}_{6}$-Phenol & 70 & Methoxyisopropylbenzene \\
\hline 165 & Dimethylisopropylphenanthrene & 108 & Neopentyloxyphenol & 91 & Methoxy-sec-butylbenzene \\
\hline 169 & Dimethylpyrene & 124 & Methylnaphthalenol & 95,115 & MMIB \\
\hline 176 & Dinaphthalenylmethane & 130 & Dimethylnaphthalenol & 97 & Methoxybutylbenzene \\
\hline 180 & Perylene & 141 & Trimethylnaphthalenol & 117 & Dimethoxytetramethylbenzene \\
\hline
\end{tabular}

THN:Tetrahydronaphthalene; $\mathrm{C}_{2}$ : Dimethyl or ethyl; $\mathrm{C}_{6}$ : Tert-butyldimethyl, ethylpropyl, or diisopropyl; AP: Acetophenone; $\mathrm{C}_{4}$ : Dimethylethyl, methylisopropyl, diethyl, sec-butyl or tetramethyl; HMPE: 1-(2-Hydroxy-5-methoxyphenyl)ethanone; CP: Cyclopent-2-enone; HTMCH: 4-Hydroxy-2,4,5-trimethylcyclohexa-2,5-dienone; MTPE: 1-(4-(Methylthio)phenyl)ethanone; MMIB: Methoxymethylisopropylbenzene.

TD mechanism and the role of EA: As Figure 1(a) exhibits, the RCs (both ca. 40\%) of phenols in $F_{1}$ and $F_{2}$ are distinctly higher than that (only $21 \%$ ) in $F_{3}$, which suggested that methanol plays an important role by nucleophilically attacking on $\mathrm{C}_{\text {acyl }}$ of $\mathrm{C}_{\text {acyl }}-\mathrm{O}-$ moiety and $\mathrm{C}_{\text {alkyl }}$ of $\mathrm{C}_{\text {alkyl }}-\mathrm{O}-\mathrm{C}_{\text {aryl }}$ moiety and resulting in the cleavage of oxygen bridges and/or ester bridges during thermal depolymerization. The $Y_{\mathrm{F} 1}$ is $13.59 \%$, almost equal to the sum of $Y_{\mathrm{F} 2}(10.37 \%)$ and $Y_{\mathrm{F} 3}(3.5 \%)$, although EA has a lower solubility parameter $\left(18.6 \mathrm{~J}^{1 / 2} \cdot \mathrm{cm}^{-3 / 2}\right)$ than methanol $\left(29.2 \mathrm{~J}^{1 / 2} \cdot \mathrm{cm}^{-3 / 2}\right)$. In addition, distinctly more kinds of phenols were detected in $F_{1}$ than that in $F_{2}$ as shown in Figure 1(b). These results indicate that the TDOM of $1 \mathrm{~g}$ SL in $20 \mathrm{~mL}$ IMEAMS is similar in amount with that of $2 \mathrm{~g}$ SL in $40 \mathrm{~mL}$ separated methanol and EA. These interesting results let us to explore whether there are the cooperative effects and what role EA plays during lignite TD in IMEAMS.

The microstructure and microenvironment of sub- and supercritical methanol are of the utmost importance for the methanolysis reaction during TD of lignite. Yamaguchi et al [9] reported that sub- and supercritical methanol at moderate density exists in hydrogen-bonding oligomers with the average chain-length of $c a .3$ molecules. Esseffar et al [10] calculated the complexes between methanol and cyclic ketones, lactones, and lactams and showed that the dominant interaction for the most stable complexes is between the oxygen carbonyl and the $\mathrm{OH}$ hydrogen of methanol. The theoretical calculations of hydrogen bond between methanol and EA were carried out using the Density Functional Theory. As Figure 3(a) shows, the hydrogen bond between the $\mathrm{O}_{\text {carbonyl }}$ of EA with the $\mathrm{H}_{\text {hydroxyl }}$ of methanol $(\mathrm{C}=\mathrm{O} \cdots \mathrm{H}-\mathrm{O})$ is formed, with $\mathrm{H} \cdots \mathrm{O}$ bond length of $0.1899 \mathrm{~nm}$ and $\mathrm{O}-\mathrm{H} \cdots \mathrm{O}$ bond angle of $168^{\circ} 2^{\prime}$. The hydrogen bonding interaction leads to electron transfer from the lone pairs of $\mathrm{O}_{\text {carbonyl }}$ to the $\mathrm{H}-\mathrm{O}$ anti-bonding orbital and slightly lengthens the $\mathrm{H}-\mathrm{O}$ bond by $2 \times 10^{-3}$ $\mathrm{nm}$, which makes the $\mathrm{O}_{\text {hydroxyl }}$ of methanol more nucleophilic. As Figure 3(b) exhibits, the $\mathrm{O}_{\text {hydroxyl }}$ of methanol is the most negative site in the methanol and EA complex. The increase in nucleophilicity of methanol makes the nucleophilic attacking easier at the initial stage of the reaction, and the $\mathrm{H}-\mathrm{O}$ bond is cleaved readily from the transition state caused by the mentioned $\mathrm{H}-\mathrm{O}$ bond extension to produce more kinds of phenols as shown in Figure 4. These results demonstrate 
that we can control the TD process by altering the microstructure and microenvironment.

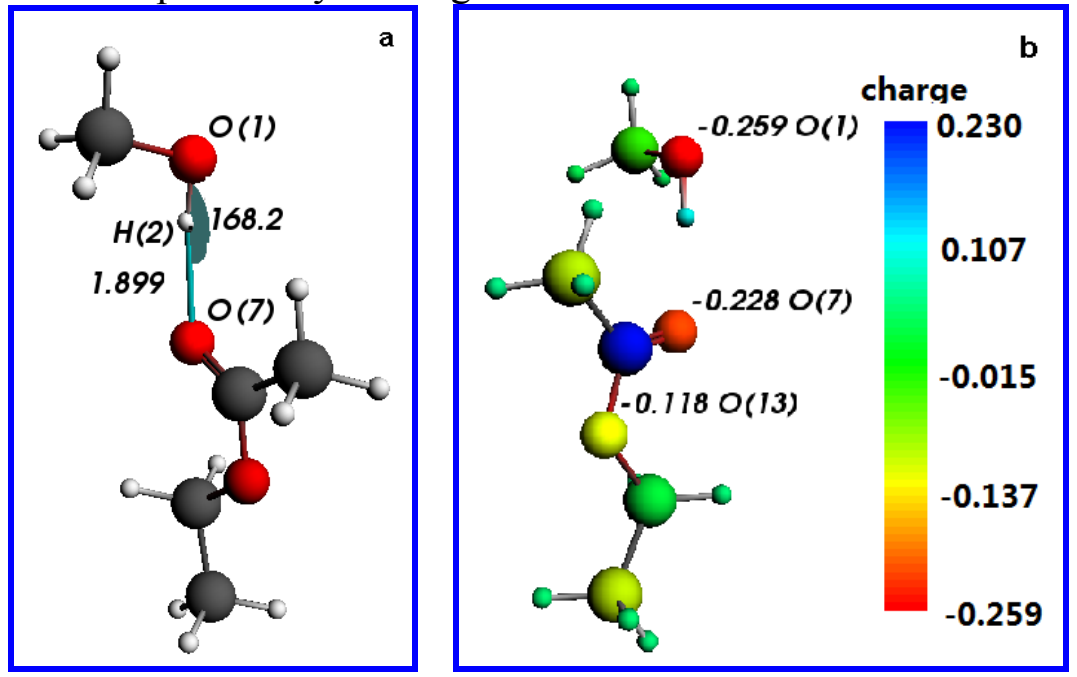

Fig. 3. Hydrogen bond (a) and charge distribution (b) of the methanol and EA complex
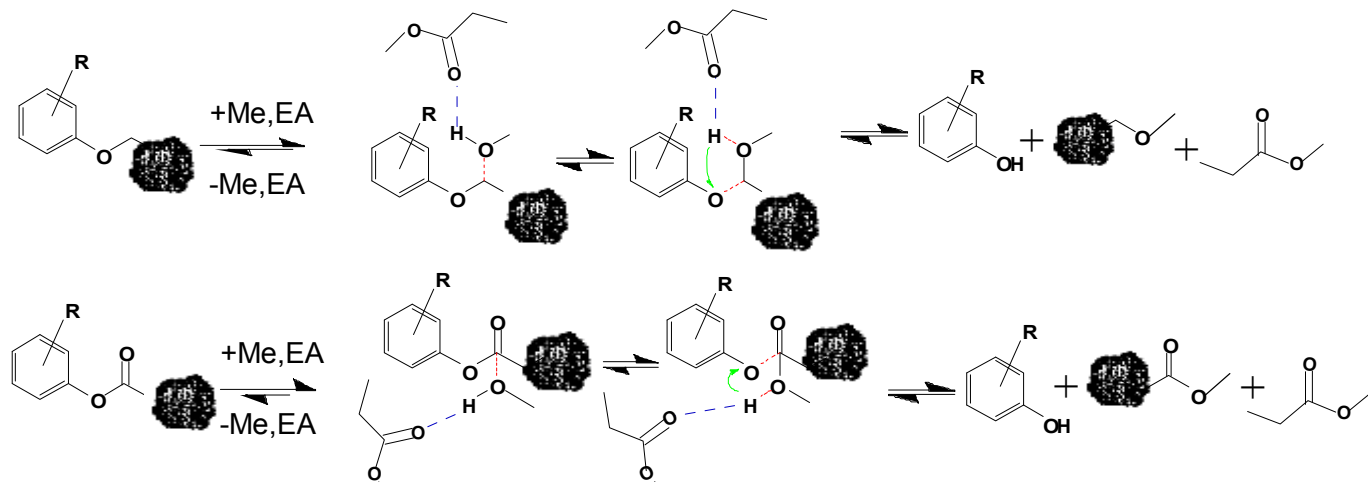

Fig. 4. Possible phenols formation mechanism during TD of SL in IMEAMS

As Figure 1(a) shows, MEs and EEs were merely detected in $F_{2}$ and $F_{3}$, respectively, whereas both MEs and EEs appeared in $\mathrm{F}_{1}$. The RC (17.6\%) of EEs in $\mathrm{F}_{3}$ is substantially higher than that (only $4.6 \%$ ) in $F_{2}$, and slightly more kinds of EEs is detected in $F_{3}$ than $F_{2}$. These facts indicate that EA possibly involve in the reversible transesterification reaction with esters and carboxylic acids already existing in lignite. EA may react with methanol to produce more nucleophilic ethanol, which in turn undergoes ethanolysis reactions with lignite.

DARTIS/IT-MS analysis of $\mathbf{F}_{1}$ : The MWD measurement of TDOM is fundamental for analyzing and determining their molecular structure. DARTIS permits rapid and direct mass spectrometric detection of gases, liquids, and complex solid samples in open air under ambient conditions. Although the ionization mechanism is still not completely understood, DARTIS mass spectra are relatively simple, dominated by molecular ions and protonated molecules $\left([\mathrm{M}+\mathrm{H}]^{+}\right)$in positive ion mode. DARTIS coupled with a mass detector make it especially suitable for the rapid MWD measurement of complex solid samples.

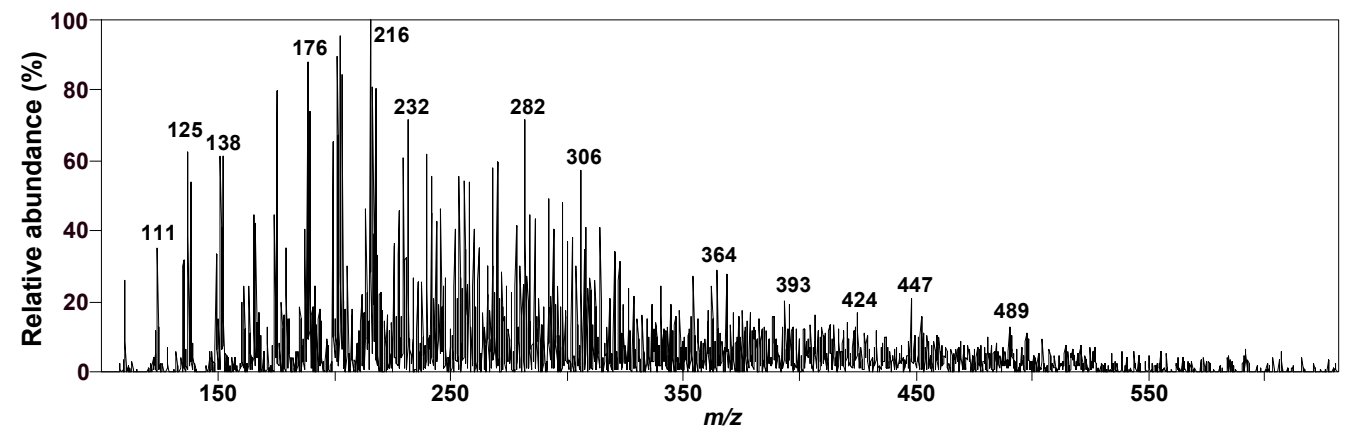

Fig. 5. MWD of $\mathrm{F}_{1}$ obtained by DARTIS/IT-MS

Figure 5 shows the DARTIS/IT-MS spectra of $F_{1}$. The main peaks of the MWD are located at $m / z$ 
120-340, and trace signals are still observed at $\mathrm{m} / \mathrm{z}$ 640. Overall, the MWD of $\mathrm{F}_{1}$ shows a normal distribution, but exhibits clearly incontinuous ion peaks (named cluster-like distribution), especially between $\mathrm{m} / \mathrm{z} 100$ and 230 . The formation of cluster-like distribution may be due to the structure similarity of the molecules in TDOM, which shows that there are many similar structure units in lignite, and that the isomeric compounds possibly produce via alkylation of lignite with methanol during TD.

\section{Conclusion}

IMEAMS proved to be effective for TD of lignite due to the microstructure alterations of methanol and the transesterification reaction of organic species in lignite with EA. Polymethyl phenols are predominant among the 196 organic compounds detected in $F_{1}$. The main peaks of the MWD of $F_{1}$ are located at $m / z$ 120-340. TD of lignite in IMEAMS is a promising method to examine lignite structure and to convert lignite macromolecules to clean fuels and value-added chemicals.

\section{Acknowledgement}

This work was subsidized by Research Award Fund for Outstanding Middle-Aged and Young Scientists of Shandong Province (Grant BS2015NJ001), Student Research Training Program from Ministry of Education (Grant 201510904006) and from Zaozhuang University, and the Fund for Doctoral Program from Zaozhuang University.

\section{References}

[1] X.S. Cong, Z.M. Zong, Z.H. Wei, Y. Li, X. Fan, Y. Zhou, et al. Enrichment and identification of arylhopanes from Shengli lignite. Energy \& Fuels 2014, 28:6745-6748.

[2] X.S. Cong, Z.M. Zong, Y. Zhou, M. Li, W.L. Wang, F.G. Li, et al. Isolation and identification of 3-ethyl-8-methyl-2,3-dihydro-1H-cyclopenta[a]chrysene from Shengli lignite. Energy \& Fuels 2014, 28:6694-6697.

[3] X.S. Cong, Z.M. Zong, M. Li, L. Gao, Z.H. Wei, Y. Li, et al. Enrichment and identification of cyclized hopanoids from Shengli lignite. Fuel Processing Technology 2015, 134:399-403.

[4] T. Takanohashi, T. Yanagida, M. Iino, D.E. Mainwaring. Extraction and swelling of low-rank coals with various solvents at room temperature. Energy \& Fuels 1996, 10:1128-1132.

[5] H. Shui, Z. Wang, J. Gao. Examination of the role of $\mathrm{CS}_{2}$ in the $\mathrm{CS}_{2} / \mathrm{NMP}$ mixed solvents to coal extraction. Fuel Processing Technology 2006, 87:185-190.

[6] H.Y. Lu, X.Y. Wei, R. Yu, Y.L. Peng, X.Z. Qi, L.M. Qie, et al. Sequential thermal dissolution of Huolinguole lignite in methanol and ethanol. Energy \& Fuels 2011, 25:2741-2745.

[7] X.S. Cong. Fractional extraction and sequential thermal dissolution of Zhundong subbituminous coal and Shengli lignite. Xuzhou, China University of Mining \& Technology, 2014.

[8] X.S. Cong, Z.M. Zong, M. Li, W.L. Wang, X.Y. Wei. Thermal dissolution of Shengli lignite in ethyl acetate: Chemical composition of the extract and mechanism analysis. Journal of Hebei Normal University (Natural Science Edition) 2014, 38:611-616.

[9] T. Yamaguchi, C.J. Benmore, A.K. Soper. The structure of subcritical and supercritical methanol by neutron diffraction, empirical potential structure refinement, and spherical harmonic analysis. The Journal of Chemical Physics 2000, 112:8976-8987.

[10] A. El Firdoussi, M. Esseffar, W. Bouab, J.L.M. Abboud, O. Mó, M. Yáñez, et al. Density functional theory study of the hydrogen bond interaction between lactones, lactams, and methanol. The Journal of Physical Chemistry A 2005, 109:9141-9148. 